\title{
El derecho al arraigo* frente al desplazamiento forzado en comunidades indígenas en Colombia ${ }^{\star *}$
}

\section{The right to hold from forced displacement in indigenous communities in Colombia}

\author{
Luisa Fernanda Hurtado; Castrillón ${ }^{* *}$; Andrés David Moncayo Clavijo ${ }^{\star * * *}$
}

\begin{abstract}
***Abogada, docente investigadora, Magíster en Educación Superior con énfasis en investigación, especialista en docencia para la educación superior Coordinadora del grupo de investigación en Derecho Constitucional categoría D (2014) Colciencias de la Universidad Libre Seccional Pereira. Correo electrónico:lfhurtado@unilibrepereira.edu.co.

****Abogado, Investigador auxiliar del Centro de Investigaciones Socio jurídicas de la Facultad de Derecho de la Universidad Libre Seccional Pereira. Integrante del grupo de investigación en Derecho Constitucional categoría D (2014) Colciencias. Correo electrónico: admoncayo@unilibrepereira.edu.co
\end{abstract}

Cómo citar: Hurtado, L.F \& Moncayo, A.D (2015). El derecho al arraigo frente al desplazamiento forzado en comunidades indígenas en Colombia. Inciso n ${ }^{\circ}$ : 153-161.

Recibido: 04/04/2015|Revisado: 19/08/2015|Aceptado: 10/12/2015

\section{Resumen}

El presente artículo de reflexión pretende describir y analizar la dificultad que representa para las comunidades indígenas el desarraigo de sus territorios y con ello la afectación a su cultura e identidad cultural, por ocasión del conflicto armado colombiano, el cual las ha obligado al desplazamiento forzado, con un enfoque de derechos. Lo anterior, en razón a que tal ruptura con su territorio significa la destrucción de modos de vida ancestrales, estructuras sociales, lenguas, identidades e incluso la desaparición de comunidades enteras por cuanto su desarrollo social, económico y cultural se relaciona completamente con su territorio. De manera que la tesis central de la presente reflexión, versa sobre cómo esa afectación es fundamento de derechos de las comunidades indígenas, derechos que por las connotaciones que presenta y representa, que van más allá del reconocimiento y protección de la diversidad étnica y cultural de la nación colombiana, desbordan los lineamientos constitucionales como la declaratoria del estado de inconstitucionalidad por la magnitud y profundidad del daño, por la supresión de una cultura, unas costumbres y una cosmovisión.

Palabras clave: Arraigo, derecho al arraigo, desplazamiento forzado, identidad, pueblos indígenas, territorio

\begin{abstract}
The present article of reflection is about the difficulty for indigenous communities uprooted from their lands and thus the effect on their culture and cultural identity, on the occasion of the Colombian armed conflict, which has forced them to forced displacement, with a focus on rights. This, on the ground that such a break with the territory means the destruction of ancestral ways of life, social structures, languages, identities and even the disappearance of entire communities as their social, economic and cultural development is completely related to their territory. So the central thesis of this reflection is about how that involvement is the foundation of rights of indigenous communities, rights for the connotations that presents and represents, beyond the recognition and protection of ethnic and cultural diversity the Colombian nation, go beyond the constitutional guidelines as the declaration of a state of unconstitutionality by the magnitude and depth of the damage, for the removal of a culture, customs and worldview.
\end{abstract}

Key words: Roots, right to hold, forced displacement, identity, indigenous peoples, territory.

\footnotetext{
*En el marco de la reflexión del presente artículo, el concepto de arraigo -v. Arraigar- entendido como "establecerse de manera permanente en un lugar, vinculándose a personas y cosas" según el Diccionario de la Real Academia Española, juega un rol fundamental para explicar las implicaciones que tiene para las comunidades indígenas su relación con la tierra y las consecuencias del desplazamiento forzado, por cuanto es el punto de partida y llegada de éste análisis reflexivo consecuente con los temas y escenarios teóricos planteados. Cabe resaltar que aunque no se encuentra en el Tesauro de la UNESCO, es imposible prescindir del mismo, menos aún usar sinónimos, bajo la copiosa pretensión de dar con alguno que si se halle en el mencionado Tesauro. Prescindir del concepto de arraigo, es suprimir el epicentro del análisis reflexivo mediante el cual se centra todo el desarrollo del presente artículo.

**Artículo de reflexión producto de discusión académica en la línea de investigación en Derechos Fundamentales del grupo de investigación en Derecho Constitucional, Categoría D Colciencias (2014) de la Facultad de Derecho de la Universidad Libre Seccional Pereira.
} 
"Sin el derecho al territorio, los derechos fundamentales

a la identidad cultural y a

la autonomía serían solo

reconocimientos formales.

[Los pueblos indígenas]

requieren para sobrevivir

del territorio en el cual están

asentados,

para desarrollar su cultura".

Francisco Rojas Birry, Representante indígena

\section{Introducción}

Desde el desierto de La Guajira hasta la selva del Amazonas, el territorio colombiano posee una inmensa diversidad cultural, cuenta con aproximadamente 87 (DANE, 2005) pueblos indígenas ${ }^{1}$ divididos en diferentes resguardos o cabildos, cada uno con sus propios usos, costumbres y cosmovisiones. En su gran mayoría, estos pueblos habitan en extensos territorios colectivos y con gran significado para los mismos, puesto que estos se consideran territorios sagrados, en los cuales reflejan hasta su identidad misma. Es más que una tierra, es un legado que ha pasado de generación en generación, es símbolo de cultura, respeto y adoración.

Sin embargo, por ocasión del conflicto armado colombiano que ya lleva más de medio siglo, en el cual se opone el Estado a diferentes actores armados, ha dejado tras de sí una compleja situación, que hasta agosto de 2015 ha dejado 7.558.854 víctimas según cifras del Registro Único de Víctimas (RUV), entre los

1. Pueblos indígenas- Se entiende por pueblos indígenas los grupos, comunidades, parcialidades e individuos descendientes de los pobladores originarios de América que tengan conciencia de su identidad étnica y cultural, manteniendo usos y valores de su cultura tradicional, así como instituciones de gobierno, de control social y sistemas normativos propios. cuales se cuentan personas que han sido desplazados, muertos, secuestrados, desaparecidos, torturados, entre otros. De esta cifra, aproximadamente 70,000 de los desplazados internos registrados son indígenas.

De acuerdo con las cifras oficiales, entre el 2004 y el 2008 se desplazaron 48.318 personas pertenecientes a pueblos indígenas (aproximadamente el 70\% del total de desplazamiento indígena registrado) (ACNUR, 2009). De manera que tal ha sido el panorama en estos largos años de conflicto, que de los 87 pueblos indígenas reconocidos en el último censo del DANE, la Corte Constitucional por medio del Auto 004 de 2009, reconoció que 34 de ellos se encuentran en peligro de extinción a causa del conflicto armado y el desplazamiento forzado y, que el pueblo Hitnú está en peligro de ser exterminado cultural y físicamente, motivo por el cual ha sido declarado, por medio del Auto 382 de 2010, como el número 35 en la lista de los 34 pueblos señalados en el Auto 004.

Pues bien, este flagelo del desplazamiento forzado genera un fenómeno de desarraigo de las comunidades indígenas con sus territorios y sus tierras, toda vez que este fenómeno, tiene una dimensión y complejidad particular, dado que se convierte en una 
grave y profunda afectación en la conservación de su identidad como pueblo y comunidad. Estos daños en sus territorios: "Ponen en riesgo la existencia de estas comunidades, pues deterioran los sistemas productivos, las habilidades, los usos y prácticas ancestrales que garantizan su subsistencia cotidiana, la trasmisión de saberes y la pervivencia cultural" (Grupo de Memoria Histórica, 2013, p. 207).

De manera entonces que el presente artículo de reflexión, aborda la dificultad que representa el desarraigo del territorio y la tierra y, consecuencialmente la pérdida de la conservación de identidades de los pueblos indígenas, que por ocasión del conflicto armado colombiano se han visto obligadas al desplazamiento forzado, desde una visión de derechos, en aras de suscitar el planteamiento acerca de la necesidad del reconocimiento de un derecho hasta el momento innominado, como sería el Derecho al arraigo para las comunidades indígenas.

\section{Importancia del territorio para los pueblos indígenas y desplazamiento forzado}

No cabe duda que todo desplazamiento forzado, sin diferenciar la población objeto del mismo, conlleva una grave afectación de derechos individuales y colectivos, profundos daños en el tejido social, familiar e interno y en relación con los demás, sumado:

"el dolor causado entre individuos, familias y comunidades aborígenes por los diversos crímenes de los que han sido víctimas; el miedo a que estas atrocidades se repitan o la situación se empeore; la desesperanza y el escepticismo frente a un Estado que no ha reaccionado como lo exige la justicia ante su tragedia, todo aquello, perpetuado en la memoria individual y colectiva de estos pueblos" (Corte Constitucional de Colombia, 2009, p. 5).

Sin embargo, cuando el desplazamiento recae sobre comunidades indígenas o étnicas adquiere dimensiones particulares, lo anterior, en razón a que:

"El significado que tiene el derecho a la tierra para los pueblos indígenas es más complejo que el simple reconocimiento de su posesión colectiva. Incluye también el reconocimiento de un conjunto de garantías culturales, sociales y políticas que son inescindibles de los derechos territoriales" (Herreño, 2004, p. 247).
Al ser forzadamente desplazados de sus territorios, se presenta un rompimiento en la relación territorio-comunidad-identidad, en otras palabras, si la relación con la tierra es sinónimo de armonía e identidad, la separación de la comunidad con la tierra genera una fractura en una representación que da vida y representación para los indígenas. Esta noción de territorio como lo afirma Ángel Herreño, se:

"Si bien conserva un marcado carácter cultural, su esencia determinante es política pues ha servido para defender el ejercicio de la autonomía por parte de las comunidades originarias frente a la institucionalidad estatal y a la sociedad mayoritaria, concretándose para ello en la demarcación de áreas territoriales en las cuales los pueblos étnicos pueden desarrollar sus proyectos de vida" (Herreño, 2004, p. 250).

Que a su vez se complementa con la noción de territorialidad, la cual:

\begin{abstract}
"Relaciona estrechamente con las formas culturales de apropiación material y simbólica de las tierras que pueblos originarios han habitado históricamente, y las cuales tienen significado, no sólo por brindar los medios para la subsistencia sino además porque son el soporte en el cual las comunidades tradicionales desarrollan sus identidades y sus visiones del mundo" (Herreño, 2004, p. 250)
\end{abstract}

Pues bien, en el fenómeno del desplazamiento forzado de las comunidades indígenas, coexiste una multiplicidad de factores que permiten dar cuenta de la magnitud del daño. Por un lado, se rompe una relación de vida y de conexión con el territorio dado el desarraigo al cual son sometidos y, por el otro, se pone en riesgo una cosmovisión e identidad dada la desintegración colectiva y social. Esta afectación de desarraigar a toda una comunidad, que opera como un todo, es decir, que recae sobre toda una comunidad sin ver sus partes individualmente consideradas, compromete la preservación de un pueblo, de sus identidades, de su cultura y de su cosmovisión.

Desde un plano de derechos, estas afectaciones comprometen desde la Constitución Nacional, una violación sistemática de derechos, razones por las cuales la Corte Constitucional, mediante Sentencia T-025 de 2004, decretó el estado de cosas inconstitucional. Esta complejidad particular que 
representa el desplazamiento de las comunidades indígenas, frente al resto de personas, trae consigo una afectación diferencial de derechos dado el nivel de afectación por las particularidades de los indígenas, en especial, por su relación de vida con el territorio. Respecto de esta naturaleza diferencial del impacto del desplazamiento sobre los pueblos indígenas, precisa la Corte Constitucional:

“(...) Esta diferenciación radica en que entremezcla facetas individuales con facetas colectivas de afectación, es decir, surte impactos destructivos tanto sobre los derechos individuales de las personas pertenecientes a las etnias afectadas, como sobre los derechos colectivos de cada etnia a la autonomía, la identidad y el territorio. Lo individual y lo colectivo del desplazamiento se retroalimentan e interactúan.

(...) la pérdida de control sobre el territorio y el efectivo ejercicio de la territorialidad, deteriora los principios fundamentales de la vida y la convivencia que fundan los procesos de construcción de identidad, los sistemas internos de autonomía, control y gobierno, los circuitos de producción y las dinámicas de enculturación" (Corte Constitucional de Colombia, 2009. p.12).

Desde el plano constitucional, la Constitución Política de 1991 dio un muy importante avance en reconocer por primera vez, la protección de la diversidad étnica y cultural de la Nación. Así mismo, a lo largo de los años, se han promulgado diversas leyes que buscan proteger aspectos propios tales como el territorio, lenguas, dialectos, derechos de propiedad y su cultura.

Tratándose de la legislación indígena, en esta se destaca: Ley 160 de 1994: Sistema Nacional de Reformas Agrarias y Desarrollo Rural y Campesino; Ley 387 de 1997: Prevención del desplazamiento forzado; Ley 649 de 2001: Circunscripción Nacional Especial; Ley 1381 del 2010: Ley de lenguas; Decreto 1088 de 1993: Por la cual se regula la creación de las asociaciones de Cabildos y/o Autoridades Tradicionales indígenas; Decreto 1745 de 1995: Derecho de Propiedad colectiva de las tierras de las comunidades negras; Decreto 2164 de 1995: Titulación de tierra a las comunidades indígenas; Decreto 1396 de 1996: Por el cual se crea la Comisión Nacional de Territorios Indígenas y se crea el Programa especial de atención a pueblos indígenas; Decreto 1320 de 1998: Reglamenta la consulta previa con las comunidades indígenas y negras para la explotación de recursos naturales dentro de su territorio. (Universidad del Rosario, 2012)

Sin embargo, pese a toda la legislación existente y la declaratoria del estado de cosas inconstitucional, el flagelo del desplazamiento forzado está llevando, tal como lo reconoce la Corte Constitucional en sus autos de seguimiento de la T-025 de 2004, a un peligro inminente de extinción de 35 comunidades, y con ello todo un valor histórico, patrimonial, cultural y social de la Nación.

Que hay una violación de derechos, eso es claro. Sin embargo: ¿Puede ser esta afectación a las comunidades indígenas tan profunda y aguda, que vuelva insuficiente los derechos reconocidos actualmente?, ¿será que acaso la visión basada en derechos de las comunidades indígenas, requiere de una interpretación más amplia y ajustada a ellos de manera que responda significativamente a su importancia y trascendencia como pobladores originarios de estas tierras?

Entre los fuertes impactos destructivos que se configuran con este tipo de desplazamiento, se encuentra el desarraigo como ruptura de una relación entre la comunidad y sus territorios ancestrales que comprende un orden de vida histórico, económico, social, espiritual y cultural, así como la pérdida de la conservación de identidades de los mismos que por ocasión de la dejación de sus territorios, lugar por tradición, costumbre e historia donde se reproducen culturalmente estos pueblos, se afecta un orden de enseñanza y legado de las generaciones mayores para con las menores, de manera que se rompen los ciclos de preservación de identidades.

También se encuentran, no menos importantes, la desintegración de las comunidades y la destrucción de sus territorios, lo que genera consecuentemente un daño profundo sobre sus estructuras culturales, cabe mencionar que todas estas afectaciones interactúan entre sí en contra de la supervivencia de los pueblos indígenas. 


\section{Del arraigo al derecho al arraigo como mecanismo de protección cultural de los pueblos indígenas}

En primer lugar, según la Real Academia Española, arraigar es: "Establecerse de manera permanente en un lugar, vinculándose a personas y cosas", que, tratándose de territorios de pueblos indígenas colombianos, enmarcan un raigambre de más de 500 años. En todo este tiempo y por razones propias de sus orígenes, los pueblos indígenas han desarrollado en sus territorios toda una cosmovisión de vida, que comprende unos usos, costumbres, dialectos y relaciones entre sí, razón por la cual el concepto del arraigo que ellos poseen con el territorio va más allá de la concepción material de las cosas, en este sentido: "Sus principios están basados en el pensamiento de la cosmovisión, la relación del hombre con la tierra, el bien y el mal, el cielo y el infierno, la luz y la oscuridad, dos componentes unidos, inherentes al ser, lo espiritual y lo material” (Agredo, 2006.29).

Relaciones tan profundas que hasta un ser inanimado como un árbol, que para la cultura occidental es una relación utilitarista como fuente de alimento, medicina, ornamento, madera, entre otras, para los pueblos indígenas, además de las anteriores, constituye una relación de vida que gira en torno al reconocimiento, en muchos casos, de símbolos de adoración, por ello y más allá de los elementos del territorio, como lo afirma Agredo:

\begin{abstract}
"Para los pueblos indígenas el significado de territorio se basa en su principio de autonomía, no como una situación de dominio sobre un lugar, sino que implica y requiere la posibilidad de la toma de decisiones sobre lo que les pertenece por naturaleza propia” (Agredo, 2006, p.30).
\end{abstract}

La importancia del territorio es tal, que desarraigar a estas comunidades de los mismos constituye un cambio radical en sus relaciones y formas de vida (la tierra, el trabajo, la participación social, la cultura, la economía y la integridad de la comunidad) y en las relaciones con los otros, como también entre los mismos miembros de la comunidad.

Como consecuencia de esto, las comunidades indígenas desplazadas son víctimas de la expulsión de sus tierras y de sus comunidades de origen, viéndose forzadas a migrar hacia los centros urbanos, fenómeno que ha adquirido importante relevancia y que se acrecienta con el impacto del conflicto armado que alimenta el desplazamiento forzado de la población indígena. Así lo afirma Pizarro: "Sin raíces, sin vínculos comunitarios, lejos de sus regiones de origen, el desplazado constituye uno de los problemas más graves de la sociedad colombiana" (Pizarro Leongómez, 1999:1).

De manera que dadas las condiciones actuales y en especial los lugares en los que se desarrolla el conflicto armado interno, en los cuales se hayan gran parte de los territorios indígenas, estos se han convertido en lugar de riesgo e indefensión para los indígenas dado que están constantemente expuestos al conflicto y al desplazamiento.

De aquí que las mayores razones por las cuales se presenta tanto interés en los territorios indígenas por parte de actores que no lo son, se deriva de factores tales como: sus recursos naturales, su valor militarmente estratégico, su valor económico y por la distancia de estos con los centros urbanos (Corte Constitucional de Colombia, 2009), situación que se ve agravada por cuanto la resolución de los conflictos territoriales siempre es bajo el uso de la violencia, en detrimento de los indígenas y con graves violaciones de derechos humanos y del derecho internacional humanitario.

El desplazamiento forzado, tratándose de derechos, genera una multiplicidad de afectaciones tanto del derecho interno como internacional, en el cual se involucra el Derecho Internacional Humanitario o bien el Derecho Internacional de los Derechos Humanos -o bien los dos- y los tratados y convenios internacionales que regulen asuntos propios de pueblos indígenas y tribales como el Convenio 169 de la OIT o la Declaración de las Naciones Unidas sobre los Derechos de los Pueblos Indígenas.

En este marco de derechos, las violaciones a las comunidades indígenas reconocidas en la constitución colombiana comprende desde la violación del principio de la dignidad humana (artículo 1), el derecho al reconocimiento y protección de la diversidad étnica y cultural de la nación colombiana 
(artículo 7), la obligación del Estado de proteger las riquezas culturales (artículo 8), las lenguas y dialectos (artículo 10), el respeto por la formación basada en el desarrollar de su identidad cultural (artículo 68), la protección de las tierras de los resguardos indígenas en cuanto estas son inalienables, imprescriptibles e inembargables (artículo 63), los derechos especiales sobre patrimonios culturales (artículo 72) y así mismo la legislación en materia de resguardos que está fundamentalmente integrada por la Ley 135 de 1961 y la Ley 31 de 1967.

Ahora bien, abordado los efectos del desplazamiento, seguidamente se analizará cómo, a partir del fenómeno del desarraigo como consecuencia del desplazamiento forzado, se debe dar reconocimiento y declaración como derecho fundamental autónomo en favor de los pueblos indígenas del derecho fundamental al arraigo -Derecho al arraigo- como derecho innominado en el ordenamiento jurídico colombiano.

En primer lugar, si bien es cierto que el ordenamiento jurídico colombiano reconoce y protege un gran número de derechos de los pueblos indígenas, no menos cierto es que este reconocimiento, que fundamentalmente concreta su margen de protección por el valor y significado cultural que representan para la Nación, no reconoce y no desarrolla un margen concreto de derechos que por su naturaleza y por las particularidades que distinguen a los pueblos indígenas, requieren de una protección basada en derechos con carácter diferencial, de manera que a partir de ellos se concreten derechos propios, fruto de sus características y de su cosmovisión del mundo.

Como se decía en el párrafo anterior, la afectación de derechos en cuanto se refiere a las comunidades indígenas comporta un carácter diferenciado, lo que implica que la atención hacia estos pueblos y la protección brindada deberá ser también con enfoque diferenciado tal como lo ha reconocido la Corte Constitucional en sus autos de seguimiento, pues los derechos que se entienden vulnerados, se reconocen con mayor daño que para el resto de la población, en razón a que estos daños conllevan poner en riesgo la existencia de estas comunidades, más aún porque:

"Los usos, abusos y disputas de los actores armados por los territorios afectan los tiempos y los lugares para llevar a cabo los rituales y las prácticas culturales propias de cada etnia. De este modo, limitan la función que estos cumplen en los procesos de socialización, cohesión, regulación e identidad de las comunidades indígenas" (Grupo de Memoria Histórica, 2013, p.279).

En el marco del desplazamiento forzado donde las comunidades indígenas son obligadas a dejar sus territorios, por las diversas razones y con los significativos impactos y daños esbozados hasta el momento, el concepto del arraigo frente a la tierra y su comunidad, cobra vital importancia y significación para la protección de la vida, cultura y ancestralidad de los indígenas, frente a quienes atentan contra ella.

El derecho al arraigo se hace fundamental por dos cuestiones trascendentales, en primer lugar, como presupuesto de reconocimiento y por cuanto elemento de protección que permita ser amparado de manera directa sin tener que recurrir a interpretaciones conexas con otros derechos $\mathrm{y}$, en segundo lugar, logrando primeramente un desarrollo jurisprudencial donde la Corte Constitucional establezca los elementos que conforman el núcleo esencial y los alcances del mismo, lograr medidas efectivas de reparación que satisfagan sus elementos fundamentales. Así pues, el derecho fundamental al arraigo de los pueblos indígenas, sirve tanto de presupuesto previo en defensa de su territorio, como posterior para su protección futura a la hora del regreso.

Esta doble vía de garantía por parte de este derecho frente a las comunidades indígenas, significa también un importante reto para el Estado colombiano, en la medida de poder lograr devolverles a las comunidades indígenas desplazadas un restablecimiento de sus necesarias condiciones para su subsistencia y reproducción cultural.

Ahora bien, el debilitamiento étnico y social y la aculturación ${ }^{2}$ prevaleciente por el intercambio cultural, genera una ruptura del entorno cultural propio debido en gran parte al "shock" intercultural. Los pueblos indígenas que han sido desplazados y obligados a emigrar de sus resguardos, sobre todo de aquellos que conservan integralmente sus identidades, viven en estado de total exclusión

2. El término aculturación se refiere al proceso por el cual el contacto continuo o intermitente entre dos o más grupos de culturas diferentes afecta mutuamente las respuestas culturales de cada uno de estos. 
cultural y lingüística, que conlleva, dada la inserción abrupta en entornos urbanos ajenos, a situaciones de miseria, indigencia, pobreza.

La conservación de su identidad originaria, cultura, tierra y territorio representan el material básico de reproducción cultural, razón por la cual, desarraigarlos de su entorno natural de forma violenta y abrupta, sin ninguna previa transición en el cambio, pone en riesgo la subsistencia de la etnia y de su identidad y cultura. Al respecto, es importante precisar lo siguiente: si bien es cierto que el derecho a la identidad cultural y a la preservación de la misma se proyecta más allá del territorio donde está ubicada la comunidad, no menos cierto es que desarraigarlos y expulsarlos de sus territorios, sí compromete la supervivencia de la misma, así como la conservación y el acceso a los lugares de importancia cultural, religiosa y política, entendiendo por cultura:

“[...] el conjunto de rasgos distintivos espirituales y materiales, intelectuales y afectivos que caracterizan a una sociedad o a un grupo social y que abarca, además de las artes y letras, los modos de vida, las maneras de vivir juntos, los sistemas de valores, las tradiciones y las creencias" (Unesco, 2001, p.1).

Desarraigar a una comunidad indígena de su entorno natural, de su espacio de vida ancestral, pone en riesgo la conservación de su cultura, pero no en todos los casos la pérdida de su identidad cultural. Al respecto, la Corte Constitucional ha dicho:

"El derecho a la identidad cultural de los pueblos indígenas es un derecho que se proyecta más allá del lugar donde está ubicada la respectiva comunidad. Esto obedece a que el principio de diversidad étnica y cultural es fundamento de la convivencia pacífica y armónica dentro del respeto al pluralismo en cualquier lugar del territorio nacional, ya que es un principio definitorio del estado social y democrático de derecho. Es este un principio orientado a la inclusión dentro del reconocimiento de la diferencia, no a la exclusión so pretexto de respetar las diferencias. Concluir que la identidad cultural solo se puede expresar en un determinado y único lugar del territorio equivaldría a establecer políticas de segregación y de separación. Las diversas identidades culturales pueden proyectarse en cualquier lugar del territorio nacional, puesto que todas son igualmente dignas y fundamento de la nacionalidad (artículos 7 y 70 C.P.). La opción de decidir si es conveniente o no dicha proyección y sobre el momento, la forma y los alcances es de cada pueblo indígena en virtud del principio de autodeterminación" (Sentencia C-882, 2011, p. 2).

Hacer esta claridad sobre identidad cultural y cultura es importante debido a que, siguiendo la Corte, en el primero, aun cuando la identidad de cada comunidad o pueblo indígena no se pierde con el desplazamiento, de manera que independiente del lugar espacial en donde se encuentre ubicado una comunidad indígena, su identidad seguirá per se siempre con ellos; tratándose de su cultura, esta sí se ve afectada por el desplazamiento, en la medida en que gran parte de la expresión de la misma se hace en y con su territorio. Por consiguiente, el entorno físico se vuelve determinante para la expresión y reproducción cultural, de paso entonces que el arraigo a sus territorios es imprescindible para la conservación cultural y ancestral de los indígenas.

Así las cosas, al desplazarse forzadamente a estas comunidades, se irrumpen los ciclos de reproducción, transformación y vida y de paso, teniéndose que trasladarse a sectores distintos, bien sea urbanos o rurales, se empieza un proceso de occidentalización cultural, es decir, cambian los patrones culturales de las comunidades indígenas para una aceptación en el nuevo entorno y con dinámicas y formas de vida totalmente disímiles frente a ellos.

Como consecuencia del desplazamiento forzado de sus territorios (que aún cuando se considera no como el único factor, pero sí muy determinante para el éxodo indígena a los centros urbanos), cada vez se ha vuelto más recurrente y problemático, sobre todo para los indígenas, la presencia de estas comunidades en los centros urbanos, que aunque conservan su identidad cultural, sus condiciones y sus factores de vida, así como los procesos y desarrollos económicos y sus tradiciones sagradas y religiosas han cambiado de forma sustancial. Así lo recopila en una de tantas memorias de la violencia el Centro de Memoria Histórica:

"Los velorios no los pudimos hacer, sacar su muerto a pasearlo por las calles y enterrarlo, tocó en bolsas porque no había cómo comprar o hacer los ataúdes y a ninguno se le pudo enterrar como 
es debido... las tradiciones de cantarle, rezarle, velarlo, pasearlo por el pueblo, que son nuestras costumbres, ni siquiera a los chiquiticos pudimos hacerles nada... Es que ni siquiera llorarlos, porque estábamos era huyendo para salvarnos los pocos que quedábamos, y hasta la enfermedad le puede quedar a uno de no llorar a su muerto" (Grupo de Memoria Histórica, 2013, p.280).

Los pueblos indígenas tienen derecho a la conservación y desarrollo de su propia identidad y cultura, la misma que se exterioriza a través de su cosmovisión, costumbres, creencias religiosas, lenguas, organización socio-política, prácticas económicas, todas ligadas a su territorio, que en síntesis engloba su forma de vida (Human Rights Everywhere, 2008).

Lo cierto es que revitalizar, fomentar y transmitir a las generaciones presentes y futuras sus historias, tradiciones orales, filosofía, literatura, lengua y sistemas de escritura cuando los hay, adoración y respeto a sus símbolos y lugares sagrados y otras manifestaciones culturales, lejos de su territorio ancestral, ajenos a su forma de vida tradicional, puede llegar a acabar por completo con unas formas de vida de gran valor para ellos mismos y para la nación colombiana. Nunca la vida en ciudad, por fuera de sus territorios y de sus lugares sagrados, será igual para los indígenas.

\section{Conclusiones}

Desafortunadamente, son múltiples las afectaciones en las que se ven inmersos los pueblos indígenas al ser desplazados forzadamente de sus territorios, las cuales llegan a golpear sus raíces y comprometer su existencia. El equilibrio de estos pueblos, basado en la sinergia constante con su territorio, permite un desarrollo de vida plena y de bienestar, por consiguiente, el desarraigo de sus territorios y su vínculo con el mismo, suprime un legado ancestral.

En tal sentido, despojarlos de sus territorios y el consecuente despojo de todo lo que los representa, constituye una negación de la diversidad y de sus valores autóctonos. Desarraigar a los pueblos indígenas de su espacio vital tiene que ser considerado el mayor daño posible que se les puede ocasionar en materia de preservación y protección de los pueblos indígenas.
Así las cosas, es importante empezar a generar el análisis del reconocimiento de un Derecho al arraigo de las comunidades indígenas sobre sus territorios, dado el valor como raíz de existencia, fuente de vida y valor auténtico de sus culturas. El conflicto armado ha ahondado con mayor ahínco en despojar, simbólica y materialmente, a los indígenas de sus entornos y territorios naturales, fundamentales para el ordenamiento social y espiritual sobre los cuales se construyen, mantienen y recrean los pueblos y comunidades indígenas.

Finalmente, el reconocimiento de los indígenas como sujetos de especial protección constitucional y como víctimas mayor violentadas junto con los afrocolombianos del conflicto armado interno y con profundos daños en su territorio, debe llevar a generar el reconocimiento del arraigo como un derecho fundamental de carácter autónomo objeto de protección, por vía interpretativa constitucional, con la obligación por parte del Estado, de su legitimación a partir de acciones específicas de protección y restitución a sus territorios para la conservación de los legados culturales propios de las comunidades.

\section{Referencias bibliográficas}

ACNUR. (2009). Documentos Refudiados América. Recuperado el 3 de Septiembre de 2015, de Agencia Nacional para los Refugiados: www.acnur.org

Agredo, G. (2006). El territorio y su significado para los pueblos indígenas. Revista Luna Azul(23), 28-32.

Auto 004 (Corte Constitucional de Colombia 2009).

DANE. (2005). Censo General . Bogotá .

Grupo de Memoria Histórica. (2013). jbasta ya! Colombia: Memorias de guerra y dignidad. Bogotá: Imprenta Nacional.

Herreño, Á. (Agosto de 2004). Evolución política y legal del concepto de territorio ancestral indígena en Colombia. EL OTRO

DERECHO, 31-32, 247. 
Human Rights Everywhere . (2008). Marco legal para los Derechos de los pueblos indígenas en Colombia. Obtenido de http://www.hrev. org

Pizarro Leongómez, E. (1999). Desplazados: factores de una "cultura de desarraigo". Revista Credencial Historia (119).

Sentencia C-882 (Corte Constitucional de Colombia 2011).

UNESCO. (2001). Declaración Universal sobre Diversidad Cultural.

Universidad del Rosario. (2012). Legislación colombiana para comunidades étnicas. Recuperado el 2015, de www.urosario.edu. co 